\title{
Imagination, Waldorf, and critical literacies: Possibilities for transformative education in mainstream schools
}

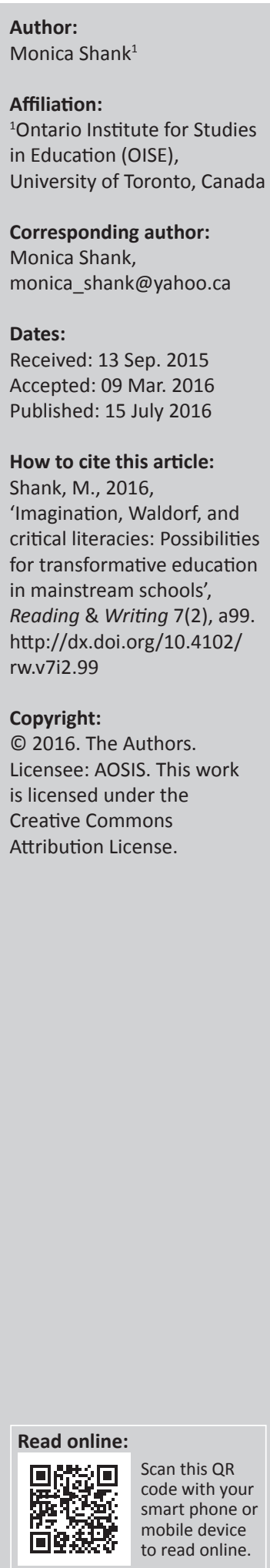

In the face of transmission-oriented national curricula, this study explores possibilities for claiming space for imagination, as 'the most powerful and energetic of learning tools' (Egan 1986), in early childhood education in mainstream Kenyan schools. Drawing from Egan's work on imagination and Cummins' Nested Pedagogical Orientations framework, this study interrogates the indispensable role of imagination in transformative education, as well as its utility in the 'transmission' of the government curriculum. This study draws insights from an initiative integrating imaginative, Waldorf-inspired pedagogies into mainstream pre-primary and early primary classrooms to explore how imagination-based pedagogies, including storytelling, creative play, poems and verses, drawing and painting, can support the development of critical literacies in young children.

'Our highest endeavor must be to develop free human beings who are able of themselves to impart purpose and direction to their lives.' - Rudolf Steiner

\section{Introduction}

Imagine a world in which all human beings are actively engaged in imagining and working towards a better world, with a burning commitment to bringing change. Imagine a world in which each person seeks to understand the bigger picture and how their thoughts and actions are part of constructing global realities. Imagine a world in which actions are taken with consideration of their long-term impact and where everyone embraces their own agency in transforming systems of oppression, exploitation and inequity.

Is such a world possible? What is the role of education in working towards such a world? In what ways is this vision, both in its construction and in its attainment, connected to imagination and literacies?

This study explores the relationships between imagination, literacies and transformative education. Emerging from work of integrating imaginative, Waldorf-inspired approaches into mainstream Kenyan schools, this study explores how imagination can enhance the teaching and learning of government curriculum, while infusing early childhood learning experiences with a transformative orientation. It examines imaginative, Waldorf-inspired approaches in relationship to critical literacies and interrogates the (irreconcilable?) tensions between the convergent thinking demanded by government curriculum and the divergent thinking promoted through imagination and transformative pedagogies. While the focus of this study is on young children in pre-primary and early primary classes, the significance of imagination as a meaning-making faculty and its role in transformative education extend, in modified ways, to literacy learning across the lifespan.

\section{Conceptual framework: Imagination and transformative education}

Imagination is central to all learning - particularly any approach to education aspiring to challenge social reproduction and contribute to societal transformation. Imagination extends beyond the production of mental images, to include engagement with human experience and possibilities well beyond the domains of learners' own experience. As an extraordinary tool of meaningmaking and of humanisation of abstract concepts, imagination is an essential part of the learning process, with far-reaching implications for pedagogy, curriculum, agency and identity. Here, we engage with Kieran Egan's constructs of imagination and its relevance to education, using 
Egan's work as a framework through which to approach the discussion of imagination and literacy education. From there, we explore relationships between imagination and transformative education, before turning our attention to some Kenyan schools that have dared to explore imaginative, Waldorf-inspired approaches to education in their teaching and learning of Kenyan government curriculum.

Kieran Egan, in his work Teaching as Storytelling, discusses the problematic ad hoc principles that many education methods are based on: the idea that children's learning proceeds from the concrete to the abstract, from the known to the unknown and from active manipulation to symbolic conceptualisation. Egan argues that these assumptions severely under-represent the abilities of children (Egan 1986). Egan's work focuses on the development of models of teaching and learning, which are fundamentally based on human beings' imaginative capabilities, celebrating children's imaginations in particular as 'the most powerful and energetic learning tools' (Egan 1986:2). His imaginationbased models offer alternatives to dominant approaches to education globally, which tend to be based on a narrow range of children's logical thinking skills - the sorts of skills that are easily grasped and measured, quite unlike imagination.

In An Imaginative Approach to Teaching, Egan asserts that: 'Engaging the imagination is not a sugar-coated adjunct to learning; it is the very heart of learning. It is what brings meaning and sense and context and understanding to the knowledge we wish to teach' (2005:36). Egan's models of imaginative teaching and learning are based on a rich image of the child as an imaginative as well as logico-mathematical thinker, as 'an energetic creator of mental images of what may never have been experienced' (1986:7). This construction of the child contrasts sharply with a deficit approach to understanding childhood abilities stemming from a fixation on logico-mathematical capabilities - the skills children are actually least good at. Egan argues that children come to school with highly developed abstract concepts, such as good or bad, survival or destruction and greed or generosity, even if they lack the vocabulary to articulate these concepts as such. Children's abilities to conceptualise binary opposites and then to mediate between them enables them to make sense of stories very far removed from their own concrete experiences and can also be used as invaluable resources in the teaching and learning of any curriculum content (Egan 1986).

Inspired by this rich understanding of children's wide range of capabilities, Egan has formulated a model of 'teaching as storytelling', in which he conceives of lessons and units not as sets of objectives to attain, but rather as 'good stories to tell in order to engage students' imaginations and emotions' (2005:12). Egan demonstrates how we can set up lessons and units like stories, creating a sense of dramatic tension or conflict at the beginning, and using rhythms of expectation and satisfaction for which children have well-developed conceptual abilities to understand (Egan 1986). Egan's model requires the teacher to identify what is most important about a topic with regards to its human dimensions: why it should matter to children and what is affectively engaging about it. Educators are then advised to identify binary opposites that can help communicate the importance of the topic and to organise content according to how it can effectively move the dramatic conflict forward. Egan emphasises the importance of human emotions and intentions in making content meaningful and how this imaginative approach is applicable throughout the curriculum. Indeed, he makes a particular point of (re) humanising science and mathematics, seeing these subjects not in a mechanical, objective way, but in a 'living context of human emotions and intentions' (Egan 1986:30).

Beyond being a rich and indispensable tool for learning, imagination is a conduit of identity formation, for divergent thinking and for the envisioning of preferred futures. Imagination plays a central role in the construction of our group affiliations, as discussed in Benedict Anderson's seminal work Imagined Communities (Anderson 2006). Taking up Anderson's work in the context of language education, Bonny Norton (2010:3) discusses the role of imagination in creating a 'sense of community with people they have not yet met, including future relationships that exist only in a learner's imagination'. Norton extends the concept of imagined communities to what she calls 'imagined identities', to explore the role of the imagination in a person's sense of self, their perceptions of their future opportunities and their sense of agency (Norton 2010).

Resisting singular, definitive interpretations of truth, imagination breeds creativity and engagement with diverse possibilities. Freedom of imagination is required to envision alternative realities and potential futures, and courses of action that could produce these futures. Indeed, the possibility of education catalysing transformation depends largely on the lively engagement of imagination. Skourtou et al. (2006) have developed a framework they call Nested Pedagogical Orientations, which describes the interrelationship between three orientations to education: transmission, social constructivist and transformative. The transmission orientation is comparable to what Freire terms the 'banking method' of education, in which information and skills are transmitted to, or 'deposited' into, learners. The social constructivist orientation involves teachers' and learners' co-construction of knowledge and understanding and the development of higher-order thinking abilities. A transformative orientation involves collaborative critical inquiry to scrutinise and understand social realities of learners' own lives and of their broader societies, and discussing and acting on ways these realities might be transformed (Cummins \& Early 2011:28-31).

The Nested Pedagogical Orientations framework views these orientations as nested within each other, rather than as isolated orientations. While the transmission orientation has the narrowest focus, the social constructivist orientation includes transmission while broadening the focus to include experiential learning, higher-order thinking and the 
co-construction of knowledge. Similarly, the transformative orientation expands upon both transmission and social constructivist orientations to include a critical orientation, an explicit focus on social justice and equity issues and the exercising of agency to intervene to transform reality (Skourtou et al. 2006:446-447).

Imagination is a potent resource in the furthering of the educational objectives of all these orientations. Most mainstream or government curricula worldwide focus on the transmission of information and skills specified in the curriculum and examinations. Transmission (or banking) approaches contribute to passivity, the veiling of reality (through fragmentation of 'information'), the suppression of agency and the monopolisation of power (Freire 2007). On the other hand, transformative orientations, or what Freire terms 'problem-posing' education, focus on the development of critical consciousness through dialogue and action.

\section{As Freire (2007) observes:}

Whereas banking education anesthetises and inhibits creative power, problem-posing education involves a constant unveiling of reality. The former attempts to maintain the submersion of consciousness; the latter strives for the emergence of consciousness and critical intervention in reality. (p. 81)

This study explores ways of bringing transformative approaches into mainstream schools, using imaginative approaches that support the transmission of information and skills necessary to excel on standardised examinations, while also broadening pedagogical orientations to include co-constructions of knowledge, critical literacies and transformative interventions in reality. Following Freire (2007:77) in acknowledging that 'thought has meaning only when generated by action upon the world', we now turn to a particular Kenyan context where action is being taken to approach a 'transmissive' curriculum with transformative orientations, embedding the schooling experience with imagination, co-construction of knowledge, creativity and agency.

\section{The context: Kenyan '8-4-4' schools}

In 2012, four primary schools, all of which use the Kenyan '8-4-4' government curriculum (8 years of primary, 4 years of secondary, and 4 years of university), embarked on a journey of seeking ways of imbuing the government school experiences with imagination. All these schools are located in areas under-resourced by government schools (two in informal settlements or urban 'slums' of Nairobi, two in rural Kenya), and all were started independently by community members or local churches concerned with the number of children out of school. These schools came to know each other through their common relationship to a small nongovernmental organisation (NGO), for which I worked as an educational advisor and which supports a number of schools and education projects in Kenya. All charge a modest monthly school fee of 300-600 KSH (about \$3-6 USD), which includes daily porridge and lunch (for some children the only food they eat in a day), although all these schools waive the fees for families who cannot afford.

Although located in different communities, these schools share similar challenges. Because of the high demand for a limited number of schools, class sizes tend to be large, particularly in the urban schools, which often have 50-80 children in each of the pre-primary classes. As the '8-4-4' system is characterised by high-stakes examinations, virtually all teaching and learning is oriented towards preparation for the examinations, beginning with 'baby class' for the 3-year olds. The combination of large class sizes and the orientation towards examinations results in a lot of what could be characterised as rote learning involving much chanting (of numbers, letters, syllables, body parts, etc.) and emphasis on the mechanics of reading and writing, as the exclusive form of assessment is the monthly written examinations. The medium of instruction is English, a second or third language for the children, who speak their ethnic languages and/or the national language, Swahili, at home. While all teachers make extensive use of familiar languages, particularly Swahili, in their classes, all written language is in English, meaning children's initial literacy instruction is in a language with which they have minimal oral familiarity. Apart from the daily 'outdoor activity' period and break time, the children spend the full day seated in crowded desks, with limited kinesthetic engagement or attention to physical development beyond that which relates to the mechanics of writing.

This description is meant to give a sense of the contextual realities in which the schools function and is not meant as an indictment of anything or anyone. Many of the teachers have extraordinary creativity, resilience and commitment to their pupils. Because of the hegemony of examinations in the ' $8-4-4$ ' system, children 'must' be given daily written homework and monthly examinations from their first days of baby class, and schools proposing to do otherwise risk having parents remove their children in favour of more 'academically oriented' schools.

The Kenyan Ministry of Education Early Childhood Development and Education Syllabus aligns completely with the ad hoc principles discussed by Egan: the content is all based on simple, concrete, everyday realities, using the 'concentric circles' model (Egan 1986) expanding outwards from the child, to the family, to the neighbourhood and the broader community (Ministry of Education, Republic of Kenya 2008). It presents an image of a child as a being that must be socialised, domesticated and disciplined into 'drawing within the lines' and the 'right answers' of schooling. The curriculum is divided into themes, such as 'Myself,' 'Our Home', 'My School' and 'Transport', which cut across the activity areas of language, mathematics, outdoor, science, social, creative, music and movement, religious education and life skills. While in theory this curriculum leaves room for discussion of diverse forms of families, or alternatives to standard clothes worn by family members (for example), in practice the 
curriculum is very prescriptive, being co-constructed with examinations which demand the reproduction of hegemonic constructions of the everyday. The language activities component of the syllabus presents an overwhelming focus on cognitive abilities and the mechanical skills of writing (Ministry of Education, Republic of Kenya 2008:1-6), although the 'general objectives of early childhood development (ECD)' mention the development of aesthetic and artistic skills and the child's exploration skills, creativity, self-expression and discovery (Ministry of Education, Republic of Kenya 2008:xi). Although there is no mention of imagination, affect or emotion anywhere in the introduction and/or overview or language activities sections of the syllabus, the inclusion of songs and stories offers possible inroads for imaginative engagement. Overall, while the syllabus itself is generally oriented towards a prescriptive transmission of knowledge and skills, in the hands of creative, imaginative teachers, the learning of this syllabus can be done in an imaginative way, while also leaving space for transformative approaches which demonstrate an orientation to education as the practice of freedom (Freire 2007).

\section{Waldorf, imagination and language education}

Eager to explore ways of bringing more life, imagination and holistic engagement to the potentially dry government ECD curriculum, these four primary schools, in collaboration with their partner NGO, developed a partnership with the Nairobi Waldorf School, to seek ways of learning from each other and mediating between Waldorf-inspired approaches and the government curriculum. There is significant alignment between Waldorf approaches and Egan's frameworks for imaginative education, transformative orientations and Freire's construction of education as the practice of freedom (Freire 2007). What follows is an exploration of Waldorf education generally and Waldorf approaches to language and literacy education specifically, with a particular emphasis on younger children.

Waldorf education begins with a commitment to the development of whole human beings, understanding the deep interconnectedness of intellectual, physical, emotional and spiritual development. Founded by Rudolf Steiner in the aftermath of World War One, the Waldorf education movement seeks to support the development of intentional, compassionate, conscientious human beings, who are mindful of our interconnected roles in working towards a more humane, just world. Waldorf education emerges from an understanding of human beings as willing, feeling and thinking beings, whose learning and growth as individuals depend on the balanced and integrated development of all three. While all deep, meaningful learning depends on the cohesive engagement of the will (through doing; physical involvement), feeling (involving sympathy; human connection) and thinking (cognitive aspects; reason), the relative dominance of these three learning faculties (which are also forms of consciousness) shifts throughout childhood development, with the will being dominant throughout the first seven years of life. The will can be characterised as the power to achieve one's goals, and its effective development, particularly through freedom of movement and active physical engagement in early childhood, can result in strong character and work ethic later in life (Edmunds 1975:31). Thus, Waldorf classrooms are very active, set up to allow children to explore, discover, construct, question and experience for themselves, with teachers' gentle guidance.

The Waldorf curriculum emerges from a deep understanding of child development and seeks to support the particular developmental tasks (physical, emotional and intellectual) children face at any given stage. Children aged 3-5, for example, are developing a keen interest in the world, supported to a large extent by freedom of movement and must be supported to follow and deepen their curiosity through the encouragement of their sometimes endless asking of questions (Van Alphen \& Van Alphen 1997). This approach to supporting children's naturally blossoming curiosity is in stark contrast to many mainstream preprimary classrooms, where children's role is largely that of answering the teachers' questions ('What colour is this?', 'What is this animal called?'), rather than being allowed the freedom to generate their own. At this stage, children's play becomes increasingly complex, with children spontaneously engaging in role plays, as they construct and act upon imaginative situations based on their own experiences and stories they have heard. Thus, in Waldorf schools, ample time is given for free imaginative play as a cornerstone of children's early learning.

Young children develop language abilities at an exceptionally rapid rate through imitation of people in their environment and through actively doing or speaking language (i.e., largely through the will) (Van Alphen 1997a). Understanding that writing and reading are built on strong oral foundations and that clear thinking emerges from clear speech, Waldorf Kindergartens (equivalent to Kenyan pre-primary classes) provide an environment rich in meaningful oral language. The foundation of the Kindergarten and early primary Waldorf experience is the story, which contributes to oral language development while also welcoming children into an imaginative world rich with feeling, beauty and intention. Indeed, virtually all content taught in pre-primary and early primary classes is presented in the form of a story. When told from the heart, stories are quickly internalised by children. Children live deeply into the experiences and realities of characters in the stories, including when the content of the stories is far removed from children's own experiences (they have no problem identifying with stories about 3-eyed giants and magical potions from talking eagles, for example). Stories help to develop children's concentration and memories, while offering a rich feast for children's imaginations, hearts and minds, as they situate learning in a context alive with human relationships, emotions and meaning.

In addition to rich experiences of stories, oral language development is supported through the recitation and internalisation of imagination-rich poems and verses, 
accompanied by meaningful gestures. Action songs and singing games also assist oral language development, while developing co-ordination, strengthening the will and nurturing a reverence for the beauty and active qualities of language. Waldorf advocates for the use of home language(s) as the media of instruction, but where this is not possible, developing strong oral foundations in the medium of instruction through meaningful exposure to and use of language is even more important. No matter what the medium of instruction, the use of multiple different languages in early childhood and beyond helps to develop flexibility of thinking, joy in diverse forms of expression and comfort with the unfamiliar. All experiences of language, whatever the language(s) may be, must be infused with life, meaning and beauty, such that children sense the intrinsic value of language and literacy learning, and their joy and inquisitiveness propels their learning forward.

Language and literacy development are also propelled through physical movement in the Waldorf approach. In contrast to the Kenyan ECD Syllabus, which emphasises the importance of fine motor skill development specifically for the mechanics of writing (Ministry of Education, Republic of Kenya 2008), Waldorf education acknowledges that there is a direct connection between the development of strong, clear movements (both gross and fine) and of clear speech and thought (Van Alphen 1997). As such, ample opportunities are provided for creative balancing, hopping, climbing in and out of things, handcrafts, beanbag exercises, circle dances, stepping and clapping rhythms and other forms of fun, meaningful movements. Movement is frequently combined with speech in the forms of poems, verses and action songs and is connected to agency, holistic participation and the confidence to act upon reality.

Overall, Waldorf approaches to language and literacy development reflect a conceptualisation of literacy that extends beyond cognitive processes to acknowledge the centrality of the imagination, the body and emotions in the construction and representation of knowledge. Waldorf pedagogies reflect an image of a child as a capable, multidimensional being, with a rich imaginative life and profound capacity for understanding through their interconnected faculties of the will, feeling and thinking. Waldorf constructions of childhood, like those of Egan, point to the gross inadequacies of cognitive-dominant approaches to early childhood education. Waldorf expands on Egan's understanding of the complementarity of affect and cognition to offer models of education that embrace the interconnectedness of the physical and spiritual, as well as the emotional and intellectual, in the development of children and indeed of all human beings.

\section{Integrating Waldorf into the mainstream}

The partnership between the Nairobi Waldorf School and these four 8-4-4 schools began with informal visits of some of the 8-4-4 teachers to Waldorf Kindergarten classes. No number of workshops, books or discussion groups could have opened up teachers' imaginations to alternatives for early childhood education as effectively as a few hours' exposure to the dramatically different paradigms underlying a Waldorf Kindergarten. It was amazing for me, as a resource person facilitating this partnership, to walk with these teachers as they began to process this radically different concept of education. 'If they don't do exams, how do they know when to promote the children to the next class?' 'How do they learn without desks, chalkboards, and notebooks?' 'If they spend all day playing, listening to stories, drawing and painting, what time do they learn?' These were among the questions teachers asked upon initial exposure to Waldorf learning environments.

These classroom visits were magical seeds which sprouted ever-expanding options for imagining how ECD classrooms can operate, be organised and conceive of success. We followed up on these ongoing visits to Waldorf classrooms with lunchtime discussions with teams of ECD teachers and school leadership at each of the schools, where teachers explored possibilities for adapting aspects of what they saw and learned into their own classrooms. In my near-weekly visits to each of the schools, I spent many hours with the teachers in the ECD classes, observing, team teaching, leading circle times and puzzling over challenges. Significantly, some Waldorf teachers also came to visit these 8-4-4 schools, which helped immensely to facilitate dialogue and mutual understanding, while offering opportunities to co-construct possibilities for the creative integration of Waldorf approaches into the 8-4-4 contexts.

We also held several Saturday workshops, facilitated by Waldorf teachers, which brought together teachers from all four of the 8-4-4 schools and offered opportunities for rich experiential learning, discussions and visioning. Among the full-day workshops was one on Developing language through stories, poems, and verses, which included explorations of appropriate stories for different developmental stages, dollmaking, beeswax modelling, drawing and, of course, storytelling. As Mary Goral asserts in her study of the process of integrating Waldorf into public schools in the United States, the combination of teacher-teacher support, regular contact with support persons for bouncing ideas and questions off of and ongoing training, were key interacting aspects of bringing about transformation, rather than relying on single workshops of 'sit and get' (Goral 2009:20). Similarly, in our development trajectories, observation, teacher-teacher collaboration, discussion groups, regular association with support persons and workshops were key interrelated components of promoting change.

Throughout all these processes, change was documented through teachers' written reflections, written documentation of teachers' discussion groups and classroom observations over more than two years. The resulting data show teachers' broadening understanding of what counts as knowledge and learning, changes in teacher-child relationships and teachers' questioning of their practice and exploring possibilities for interrupting the status quo. 
Transformations in teaching and learning in the ECD classrooms were gradual, often stuttering, but transformational nonetheless. Teachers' broadening conceptualisations of knowledge and learning were manifested in a decreasing reliance on writing and reading as the main sites of instruction and assessment and an increasing focus on oral language development, particularly through stories, verses, songs and poems. In many classes, songs and verses went from being energisers or offering a break from seat-learning to being integrated centrally into the learning of the curriculum. In a written reflection, one teacher expressed surprise at how much learning could take place without reading or writing, and this discovery was reflected in her classroom in increased movement, less time spent in desks, the introduction of materials such as beanbags and homemade shakers and the very frequent use of action songs and verses. Previously spending hours every day distributing, collecting and correcting notebooks for simple writing exercises (a chaotic process in which some children spent only a few minutes on the intended writing task), an increased focus on oral language development decreased some of the need for the endless notebook process, while also engaging children's hearts and bodies in a joyful learning process which energised rather than exhausted children. These practices reflected an expanding conceptualisation of literacy beyond a mechanical, cognitive process towards one which accounts for the role of the body, the imagination and emotions in the construction and representation of knowledge.

Another teacher's reflections articulated a growing determination to 'involve learners from head to toes...every day for holistic growth and coordination, e.g. through songs'. A primary teacher, previously extremely focused on academic learning oriented towards examination, stated: 'How wonderful it is to involve a child's heart, head and limbs in his/her growth and learning'. Along with these expanding understandings of what constitutes literacy and learning came a sense of urgency to challenge society's narrow expectations of school learning as reading and writing, and speaking English. One teacher echoed the comments of several other teachers and school administrators when she wrote, 'We must sensitise parents on the kinds of knowledge and skills which must be taught to young children'. In a context where pre-primary examinations are not mandated by the Ministry of Education, these attitude shifts could result in the creative development of alternative pre-primary assessment models at these schools in the future.

The introduction of imaginative, Waldorf-inspired pedagogies shifted teacher-pupil relationships in ways which affirmed the agency of the children by offering greater freedom and by being less prescriptive. Several teachers began welcoming free drawing or scribbling, rather than only joining the dots and colouring in the lines. Some teachers began building singing and clapping into their daily routines to signal transitions in lessons and expectations for behaviour, rather than yelling instructions like 'Keep quiet!' and 'Sit down!' One teacher wrote that he was bringing more 'movement into class where the child is the centre of everything, while the teacher is to guide and facilitate materials and songs. The teacher is to be creative and to be a role model'.

Many of the teachers found opportunities to push restrictive desks out of the way, or to move children outside, in order to spend more time in active movement, such as circle time. Stories entered into many classes, including stories told in the familiar language of Swahili, for maximum engagement with imagination and emotions, which are very difficult to access in an unfamiliar language. Particularly when told in a circle, stories became participatory, with children collectively transforming into various characters to perform the actions taking place in the story. Often, the same story was told multiple times, including in English once the story became familiar, and the repetition offered opportunities for greater participation of the children. The repetition and increasing sense of ownership of the stories also allowed the children to internalise the stories (including vocabulary and repetitive phrases), which then quite naturally re-emerged in their creative play time and drawings, including in creative reversionings of the familiar stories.

Because these are still 8-4-4 schools and the syllabus still had to be covered, teachers worked on developing stories which emerged from the thematic areas of the syllabus. Although the syllabus is full of simple, everyday things, when infused with imagination ordinary things like household utensils can take on extraordinary meaning. For example, spoons, forks and knives can be playing happily together, when they encounter a challenge they must overcome. They work together, using their respective virtues, to overcome the challenge. A story like this engages the imagination, brings out human qualities, while also bringing out the essence of 'spoon', 'fork' and 'knife' by exploring creative possibilities for their unconventional uses, in a way quite impossible when we just teach, 'This is a spoon, we use it for eating githeri'. These practices, by creating space for imagination and children's creative participation, challenge the teacher's monopoly on knowledge and re-position learners as active creators, participants and interpreters, rather than idle recipients of skills and knowledge.

These practices also signal teachers' questioning of reproductive models of education and represent bold interventions towards changing the educational status quo. Increased time spent in circles rather than teacher-fronted classrooms, the introduction of storytelling, and the creation of space for activities which are not directly examinable represent challenges to traditional classroom power relations and rigid standardisation of learning. Additionally, the unapologetic use of Swahili in storytelling and other activities is a move towards engaging learners' imaginations in a medium which allows them greater flexibility of thinking and increased power to make interventions. While also using English in these activities, particularly once children's confidence has already been built, and in a few cases also claiming space for songs or other contributions in the 
children's mother tongues, this more multilingual approach supported engagement with options of ways of conceiving of and naming the world, while also opening up space for identity affirmation and negotiation.

One teacher stated her need to 'fully understand the development of children'. Many of the teachers, in their thinking and practice, demonstrated a move beyond 'triviastyle' education (Egan 2005) towards questioning the bigger developmental tasks of children (physical, emotional and intellectual) which education must support. Another teacher wrote that 'materials must be improvised and not bought, e.g. made by the teacher, children, and parents'. Teachers taking ownership of making their own dolls, beanbags, musical instruments and other materials, often with the participation of children, gave the materials a living nature, open to adaptation and creative intervention. Incomplete materials, such as dolls without faces, demanded engagement of the imagination to complete and left room for interpretation and change.

In general, the transformations documented in these classrooms represent a broadening understanding of what can constitute knowledge and learning, shifts in traditional top-down teacher-pupil relations and an unsettling of the educational status quo.

\section{Imagination, critical literacies and Waldorf}

The imaginative, Waldorf-inspired approaches to literacy interrogated in this study are particularly conducive to the development of critical literacies in young children. Imagination resists singular, definitive interpretations of truth, and imaginative approaches create space for each learner to negotiate their own interpretations, in ways which defy closure or conformity. By creating space for each learner to experience and interact with living content, imagination necessarily opens doors to engagement with possibilities, divergent thinking and diversity.

In Literacy and Power, Hilary Janks (2010) details the significance of practices of design and re-design, in addition to analyses of power, access and diversity, in transformative critical literacies practices. Young children are prolific at redesigning, or re-versioning, texts to which they are exposed, and these Waldorf-inspired approaches offer children freedom to engage with and re-design texts (broadly conceived) imaginatively and in varieties of media. Putting productive practices at the core, these approaches nurture learners' creative agency, by offering them living, dynamic content which they can negotiate, interpret and act upon, including in their imaginative play, their drawings and paintings, and their creative re-tellings of stories. Importantly, by not limiting 'learning' or 'literacy' to the (re)production of written letters, words and sentences, these imaginative and creative practices engage and nurture 'multiliteracies,' which The New London Group (1996) propounds as a plurality of literacies of increasing importance within the changing socio-economic conditions and communication practices associated with globalisation.

Freire (2007), in describing the 'banking' or transmission approach to education, notes that:

The more students work at storing the deposits entrusted to them, the less they develop the critical consciousness which would result from their intervention in the world as transformers of that world. The more completely they accept the passive role imposed on them, the more they tend simply to adapt to the world as it is and to the fragmented view of reality deposited in them. (p. 73)

Most standardised national curricula (and examinations) lead to the fragmentation of knowledge, leading to ahistorical and apolitical (and a-human) collections of facts and skills 'which they do not perceive as interacting constituent elements of the whole' (Freire 2007:104). Waldorf-inspired approaches present content in holistic ways, encouraging the development of understanding of how everything fits together in a meaningful whole (Van Alphen 1997). In addition, the integration of intellectual development with that of the body, feelings and intuition leads to fuller understanding of meaning and relevance and of how language and knowledge act on us and on the world.

Comber and Nichols (2004) question the conditions that allow, or even require, the creation of classrooms where understanding instructions and carrying them out with precision is the benchmark of success and in which conformity seems to dominate constructions of giftedness and academic achievement. In a way which echoes Comber and Nichol's (2004) observations, in the mainstream 8-4-4 classrooms observed, the omnipresent constructions of 'fast' and 'slow' learners is entirely based on the ability to conform to the demand for very specific 'right answers' in the schools. Even where a supposedly creative activity like drawing exists (in examination questions like 'draw a cup'), there is no creative license allowed, and the attainment of a check mark depends upon the ability to reproduce the standard picture, devoid of beauty or imagination. The introduction of imaginative, Waldorf-inspired approaches into these schools was an intervention aimed at creating spaces in which children could create alternatives to hegemonic constructions of 'knowledge', by centring learners' agency and multimodal productive literacies.

Observations of children in Waldorf-inspired classrooms align with Comber's (2001) observation that 'a great deal of [young children's] play is about the negotiation of power and identity through language' (Comber 2001). When imaginative stories enter into children's thinking, the children engage with them in their creative play, taking on the identities of different characters, and changing the stories through their interactions with them. Often, through these processes of deep engagement and organic re-design, critical questions gradually emerge: 'Why should the stepmother be so mean?' 'What if the brother goes back home after the quarrel?' The constant engagement of the 
imagination, including through creative play, drawing, painting and storytelling allows children to claim their agency 'to think and imagine otherwise' (Comber 2001). Indeed, the imaginative practices of these Waldorf-inspired classrooms defy stagnation by inviting children's ongoing creative interventions, contributing to experiences of 'reality as a process, as transformation, rather than as a static entity' (Freire 2007:92).

Janks states that, 'Different ways of reading and writing the world in a range of modalities are a central resource for changing consciousness' (Janks 2010:24). Waldorf-inspired approaches functionally expand notions of literacy to include diverse modes of communication and expression, including drawing, movement, painting, imaginative play, handcrafts, storytelling and other oral modalities, and the celebration of multilingualism. These multimodal pedagogies use imagination as a central resource, while creating space for children's diverse 'ways with words' (Heath 1983). Putting productive practices at the core, these Waldorf-inspired approaches expand upon critical literacies perspectives which are predominantly cognitive or analytical, noting that children's critical faculties are not limited to cognition and are much greater than what they can articulate within traditional constructs of literacy, or even within the verbal discussions of texts which frequently factor prominently in critical pedagogies. These creative literacy practices allow 'learners [to] assume from the beginning the role of creative subjects' (Freire 1972, as quoted in Janks 2010:13). The positioning of learners as creative subjects follows Comber (2001) in 'assum[ing] young people's complex productive and analytical capacities for engagement with what really matters', and treating young people not 'as infants, but with respect and expectation' (Comber 2001).

\section{Conclusion}

While this study has explored possibilities for transformation in mainstream schools using government curriculum, the transformations in the four schools involved in this particular initiative are far from 'complete' or free from challenges. Ongoing significant challenges to the integration of imaginative, Waldorf-inspired approaches include parental objections and misunderstandings, rigid assessment models, large class sizes and the unfamiliar medium of instruction (English). Moving forward, there is an urgent need for greater engagement of parents, and for continued movement towards more fluid classrooms, still greater emphasis on oral language development and increasing space for multilingualism. In addition, there is a critical need to imagine alternative assessment models which encompass holistic child development and pay heed to children's multimodal communicative and expressive abilities, for the sake of understanding and supporting children's development and not for the sake of categorising students or quantifying learning. Significantly, the examinations children are subjected to in pre-primary schools are not mandated by the government, but are purchased by the schools in order to train young children on examination-writing skills and to satisfy pressures for 'evidence' of learning. While I believe schools have a moral imperative to assist children to succeed on the high-stakes national examinations (taken in class 8, which serve as a gate-keeper to secondary school opportunities), I reject the presumption that disciplining young children into the reproductive, imagination-less structures of testing from the age of 3 is an effective way of preparing for examination excellence 11 years later. The development of strong linguistic foundations, a keen love of learning and the agency of productive literacies will serve children much better in examination success than regimenting lifeless learning into early childhood education.

That said, these 8-4-4 schools still have the responsibility to effectively teach the government ECD syllabus. A key argument of this study is that imagination, as 'the most powerful and energetic of learning tools' (Egan 1986:2), is a key resource in all forms of learning, whether oriented towards the transmission of the knowledge and skills mandated by the government curriculum or working towards social constructivist and transformative ideals. While I would love to re-design the Kenyan ECD syllabus, the focus of this study is to explore possibilities for working within the confines of the current syllabus to infuse imagination and transformative pedagogies into early childhood learning, while also ensuring our children have access to bright futures by excelling on high-stakes national examinations. While there are significant, and perhaps irreconcilable, tensions between the rigidity of government curriculum and the divergent thinking promoted through imagination and critical literacies, I believe that the directions pointed to in this study can support young people to access the dominant system through mastery of its codes, while simultaneously supporting them to develop the attitudes, agency and vision to subvert neoliberal government agendas and standardising policies, to contribute to constructing just, equitable, imaginative futures.

\section{Acknowledgements Competing interests}

The authors declare that they have no financial or personal relationships which may have inappropriately influenced them in writing this article.

\section{References}

Anderson, B., 2006, Imagined communities: Reflections on the origin and spread of nationalism, Verso, London.

Comber, B., 2001, 'Critical literacy: Power and pleasure with language in the early years', Australian Journal of Language and Literacy 24(3), 168-181.

Comber, B. \& Nichols, S., 2004, 'Getting the big picture: Regulating knowledge in the early childhood literacy curriculum', Journal of Early Childhood Literacy 4(1), 43-63. http://dx.doi.org/10.1177/1468798404041455

Cummins, J. \& Early, M., 2011, Identity texts: The collaborative creation of power in multilingual schools, Trentham Books, Stoke on Trent, UK.

Edmunds, F., 1975, Rudolf Steiner's gift to education: The Waldorf schools, 3rd rev. edn., Rudolf Steiner Press, London.

Egan, K., 1986, Teaching as storytelling, The University of Chicago Press, Chicago.

Egan, K., 2005, An imaginative approach to teaching, Jossey-Boss, San Francisco.

Freire, P., 1972, Cultural action for freedom, Penguin, Harmondsworth. 
Freire, P., 2007, Pedagogy of the oppressed, 30th Anniversary edition., Continuum, New York.

Goral, M., 2009, Transformational teaching: Waldorf-inspired methods in the public schools, Steiner Books, Great Barrington.

Heath, S.B., 1983, Ways with words, Cambridge University Press, Cambridge.

Janks, H., 2010, Literacy and power, Routledge, New York.

Ministry of Education, Republic of Kenya, 2008, Early childhood development and education syllabus, Kenya Institute of Education, Nairobi.

New London Group, 1996, 'A pedagogy of multiliteracies: Designing social futures', Harvard Educational Review 66(1), 60-92. http://dx.doi.org/10.17763/haer.66.1. 17370n67v22j160u
Norton, B., 2010, 'Identity, literacy, and English language teaching', TESL Canada Journal 28(1), 1-13.

Skourtou, E., Kourtis-Kazoullis, V. \& Cummins, J., 2006, 'Designing virtual learning environments for academic language development', in J. Weiss, J. Nolan \& $\mathrm{V}$. Nincic (eds.), International handbook of virtual learning environments, pp. 441-467, Springer, Dordrecht.

Van Alphen, C., 1997a, The Waldorf approach to writing and reading in grades 1 \& 2 Zukunftsstiftung Entwicklungshilfe, Bochum, Germany.

Van Alphen, P. \& Van Alphen, C., 1997, Child development: Based on the insights of Rudolf Steiner and as used in Waldorf/Steiner schools, Zukunftsstiftung Entwicklungshilfe, Bochum, Germany. 